\title{
Peritoneal Dialysis in Patients with Primary Cardiac Failure Complicated by Renal Failure
}

\author{
T.T. Cnossen ${ }^{a} \quad$ J.P. Kooman ${ }^{a} \quad$ C.J.A.M. Konings ${ }^{c} \quad$ N.H.M.K. Uszko-Lencer ${ }^{b}$ \\ K.M.L. Leunissen ${ }^{a}$ F.M. van der Sande ${ }^{a}$ \\ ${ }^{a}$ Division of Nephrology, Department of Internal Medicine, and ${ }^{b}$ Department of Cardiology, Maastricht University \\ Medical Center+, Maastricht, and ' ${ }^{\mathrm{D}}$ epartment of Internal Medicine, Catharina Hospital Eindhoven, \\ Eindhoven, The Netherlands
}

\section{Key Words}

Heart failure - Peritoneal dialysis $\cdot$ Renal failure $\cdot$

Hospitalization time

\begin{abstract}
Background/Aims: Clinical outcome in cardiorenal syndrome type II and treated with peritoneal dialysis (PD). Methods: Retrospective analysis over a period of 10 years. Results: Twenty-four patients with mean age at start of dialysis of $67 \pm 10$ years had mean survival on dialysis of 1.03 \pm 0.84 years (median survival 1.0 year). The number of hospitalizations for cardiovascular causes were reduced (13.7 \pm 26.5 predialysis vs. $3.5 \pm 8.8$ days/patient/month postdialysis, $p=0.001$ ). Patients who survived longer than the median survival time $(n=12)$ also had a reduced number of hospitalizations for all causes $(3.7 \pm 3.8$ predialysis vs. $1.4 \pm 2.1$ days/ patient/month postdialysis, $p=0.041)$, a lower age (62 \pm 10 vs. $71 \pm 8$ years, $p=0.013$ ) and fewer had diabetes ( 2 vs. 7 patients, $p=0.039$ ), but left ventricular ejection fraction was not different. Conclusion: After starting PD for cardiorenal syndrome, hospitalizations for cardiovascular causes were
\end{abstract}

reduced for all patients. Survival after starting PD is highly variable. Age and diabetes seem to be significant prognostic factors, but not left ventricular ejection fraction.

Copyright $\odot 2010$ S. Karger AG, Basel

\section{Introduction}

The incidence of congestive heart failure (CHF) is increasing due to a growing number of cardiovascularly compromised patients. Treatment of hypervolemic patients with treatment-resistant $\mathrm{CHF}$ complicated by progressive and permanent chronic renal insufficiency, also known as the cardiorenal syndrome (CRS) type II [1], is notoriously difficult. Ambulant intermittent treatment with intravenous diuretics has been a rational option [24]. However, diuretic resistance may lead to recurrent episodes of pulmonary congestion and edema. The purpose of peritoneal dialysis (PD) is gradual fluid and excess sodium removal. PD offers potential advantages in patients with CRS type II, even when not complicated by endstage renal failure [5-25].

\section{KARGER}

Fax +4161306 1234 E-Mail karger@karger.ch www.karger.com
(C) 2010 S. Karger AG, Base

0253-5068/10/0302-0146\$26.00/0

Accessible online at:

www.karger.com/bpu
T.T. Cnossen, MD

Department of Internal Medicine, Division of Nephrology

Maastricht University Medical Center+

P. Debyelaan 25, NL-6229 HX Maastricht (The Netherlands)

Tel. +31 43387 5007, Fax +31 43387 5006, E-Mail nynke.cnossen@ mumc.nl 
Several small studies have shown that PD may be useful in the treatment of CRS type II [5-24]. In the majority of the patients, an improvement of the functional status $[6,7,9,14-19,21-23]$ and a reduction in hospitalization was observed compared to historical data [13-15, $20-23]$.

The aim of the present retrospective study was to investigate the outcome of $\mathrm{PD}$ in patients with CRS type II. Secondly, the effect of PD on hospitalization during the 1st year after starting dialysis was compared with the last year before starting dialysis. Thirdly, potential prognostic factors for survival were studied.

\section{Patients and Methods}

All patients treated with PD in our centre between August 1, 1997, and January 1, 2008, were screened for the primary cause of severe renal failure. Data on patients with CRS type II [1] were retrieved from patient charts in the medical archive. The end of the follow-up period was 1 January, 2009. Generally, in our hospital, we use PD primarily as a treatment option for CRS only in patients with severe renal failure, and not as a routine option in patients with less advanced stages of renal failure. All patients used commercially available glucose- and non-glucose-containing (e.g. icodextrin) dialysis solutions (Baxter Healthcare, IRL, Dublin, Ireland)

Data were collected on comorbidity, laboratory investigations, renal function, body weight, C-reactive protein (CRP), left ventricular ejection fraction (LVEF) on echocardiography and medication, duration and reasons for hospitalization, and causes of mortality.

Blood laboratory investigations included hemoglobin, serum albumin, plasma urea and plasma creatinine. Residual glomerular filtration rate (GFR) was calculated using Modification of Diet in Renal Disease (MDRD) formula.

Adequacy of $\mathrm{PD}$, determined by Kt/V urea was assessed from the 24-hour peritoneal effluent and urine collections, and calculated using PD Adequest ${ }^{\circledR} 2.0$ for Windows (Baxter Healthcare).

The study was approved by the Ethical Committee of the Maastricht University Medical Center+, Maastricht, The Netherlands.

\section{Statistical Analysis}

Results are expressed as mean values and standard deviations. Because the data of our study population are asymmetrically distributed, nonparametric tests as the Mann-Whitney U and Wilcoxon signed rank tests, were used to analyze the differences before and after starting dialysis and the outcome between patients who survived less and longer than the median survival time. Survival was assessed by Kaplan-Meier survival analysis. Due to the limited number of patients, Cox regression analysis was not used.

A $p$ value of $<0.05$ was considered significant. All of the statistical analyses were done using SPSS for Windows statistical software (release 16.0).

PD in Patients with Primary Cardiac Failure and Renal Failure

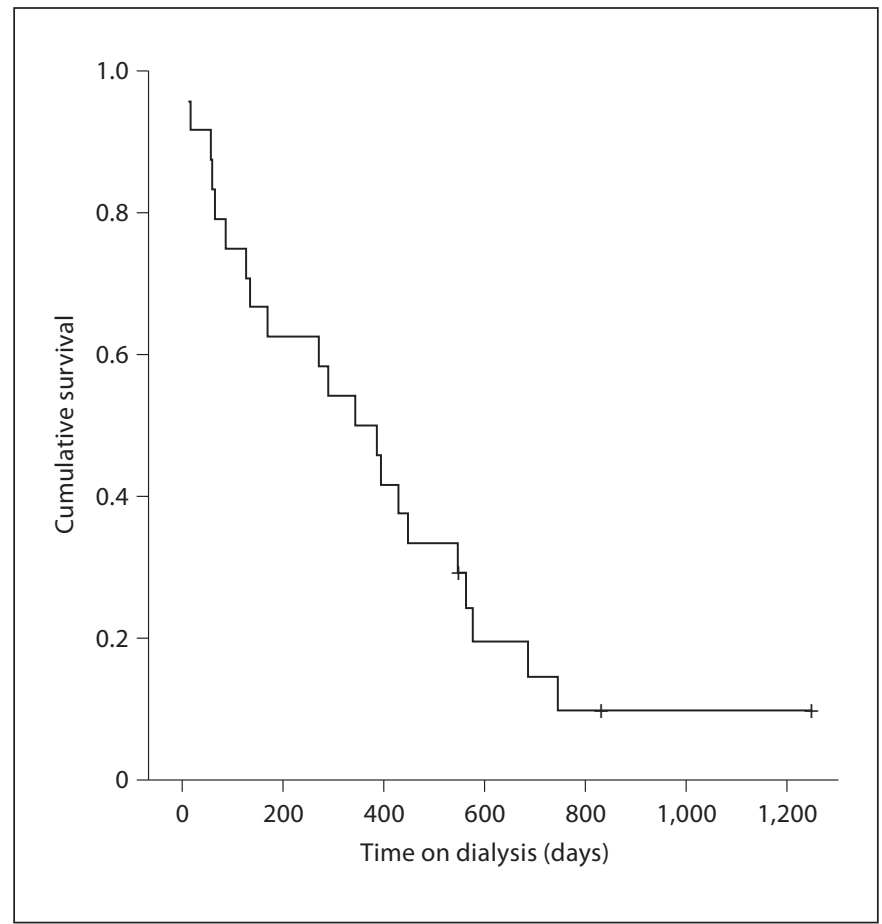

Fig. 1. Kaplan-Meier survival curve.

\section{Results}

Over a period of 10 years, 24 patients (6 women and 18 men) known with primary treatment-resistant CHF complicated by severe renal failure (CRS type II) were treated by (incremental) chronic ambulatory PD. Six patients (25\%) started initially with 1 dwell per day (incremental continuous ambulatory PD). The other patients started with 4 dwells of 2,000 $\mathrm{ml}$ per $24 \mathrm{~h}$. The underlying cause of renal failure was mainly chronic glomerulosclerosis/atherosclerosis. In absence of hematuria or significant proteinuria, kidney biopsies were in general not performed. Commercially available glucose- and non-glucose-containing (e.g. icodextrin) solutions were used. Ten patients (42\%) started first with intermittent hemodialysis (IHD) and switched later to PD. Mean time on IHD was $35 \pm 60$ days. Twelve patients (50\%) with a hypervolemic status due to treatment-resistant CHF started with dialysis in an acute setting (CRS type I). At the end of the follow-up period, 3 patients were still treated for more than 12 months. Mean duration of dialysis was $1.03 \pm$ 0.84 years (median survival time 1.0 years; range 10 days to 41 months). The cumulative survival after starting dialysis is shown in a Kaplan-Meier curve (fig. 1).

Blood Purif 2010;30:146-152 
Table 1. Characteristics of patients in groups A and B

\begin{tabular}{lcc}
\hline & Group A & Group B \\
\hline Patients & 12 & 12 \\
Men, \% & $11(92)$ & $7(58)$ \\
Diabetes, \% & $7(58)$ & $2(17)^{*}$ \\
Start in acute setting, \% & $7(58)$ & $5(42)$ \\
Initial treatment with IHD & 5 & 5 \\
Use of icodextrin, \% & $5(42)$ & $8(67)$ \\
Age at PD start, years & $71.3 \pm 8.0$ & $61.5 \pm 9.6^{* *}$ \\
Mean body weight, kg & $74.9 \pm 13.0$ & $64.8 \pm 25.9^{* * *}$ \\
Time on IHD, days & $18 \pm 36$ & $52 \pm 75$ \\
Mean MDRD, ml/min/1.73 $\mathrm{m}^{2}$ & $15.0 \pm 9.0$ & $15.3 \pm 10.7$ \\
Mean hemoglobin, mM ${ }^{\mathrm{a}}$ & $6.8 \pm 0.99$ & $6.7 \pm 0.78$ \\
Mean diuresis, ml/24 h & $928 \pm 878$ & $1,333 \pm 552$ \\
Mean GFR, ml/min & $15.7 \pm 9.6$ & $14.3 \pm 13.7$ \\
Mean serum albumin, g/l & $34.4 \pm 6.1$ & $34.2 \pm 7.5$ \\
Mean CRP, mg/l & $9.0 \pm 10.2$ & $26.1 \pm 31.5$ \\
LVEF predialysis, \% & $32 \pm 17$ & $34 \pm 16$ \\
\hline
\end{tabular}

$\mathrm{CAPD}=$ Continuous ambulatory peritoneal dialysis.

${ }^{*} \mathrm{p}=0.039,{ }^{* *} \mathrm{p}=0.013,{ }^{* * *} \mathrm{p}=0.000$.

a Correction factor: $1 \mathrm{~mm}$ is equivalent to $1.611 \mathrm{~g} / \mathrm{l}$.

Mean age at start of dialysis was $67 \pm 10$ years. Mean diuresis before start of dialysis was $1,403 \pm 756 \mathrm{ml}$ per $24 \mathrm{~h}$, and mean GFR was $14.8 \pm 12.1 \mathrm{ml} / \mathrm{min}$. Eleven patients (46\%) did not have ESRD (highest GFR was 52.2 $\mathrm{ml} / \mathrm{min}$ ). Eight patients had heart failure because of ischemic cardiomyopathy, 12 patients had a dilated cardiomyopathy and 4 patients had a dilated ischemic cardiomyopathy. Most patients also had valvular disease. There were no differences between patients with known different types of cardiomyopathy.

Echocardiography was performed in all patients before starting dialysis. LVEF was $33 \pm 16 \%$. A second echocardiography was performed in 18 patients. LVEF was either stable $(n=2)$, improved $(n=11)$ or aggravated $(\mathrm{n}=5)$. Mean LVEF at the second echocardiography was $34 \pm 13 \%$ (NS).

Body weight was reduced from $68.7 \pm 21.9 \mathrm{~kg}$ before to $60.4 \pm 25.3 \mathrm{~kg}$ after starting PD $(\mathrm{p}=0.045)$. Adequacy of PD could be retrospectively retrieved from only $10 \mathrm{pa}$ tients. Mean total Kt/V was $1.98 \pm 0.63$, mean $\mathrm{Kt} / \mathrm{V}$ of $\mathrm{PD} 1.05 \pm 0.28$, and mean renal Kt/V $0.54 \pm 0.68$.

Twenty-one of the 24 patients dropped out during the follow-up. One patient was transferred to another dialysis centre after having been treated for more than 18 months. Four patients (17\%) were withdrawn from treatment on their own initiative after, respectively, 54 days, 58 days,
19 months and 24 months of dialysis, and died within a few days. Eight patients (40\%) died due to a cardiovascular event such as myocardial infarction, heart failure, brain stem infarction, cerebrovascular accident and sudden death. One patient (5\%) died after pneumonia and another patient due to ischemic colitis. The cause of mortality was unknown in 7 patients (35\%), but was not attributed to any complication related to PD treatment.

Hospitalization, expressed as the number of hospitalization days per patient per month, was compared between the last year before starting dialysis and the first year after starting dialysis. For all patients, the hospitalization time for all causes was $14.0 \pm 26.4$ days/patient/ month before and $7.4 \pm 10.5$ days/patient/month after starting dialysis (NS). Reasons for hospitalization were hernia umbilicalis, diabetic foot, implantation of pacemaker or internal cardiac defibrillator, gastric perforation, pulmonary embolus and infections such as peritonitis $(\mathrm{n}=4)$, pneumonia and catheter sepsis during temporary IHD $(\mathrm{n}=1)$. Hospitalization time for cardiovascular causes was $13.7 \pm 26.5$ days/patient/month before and $3.5 \pm 8.8$ days/patient/month after starting dialysis $(\mathrm{p}=0.001)$, equivalent to a $74 \%$ reduction.

Patients who survived less than the median survival time (group $A ; n=12$ ) were compared with patients who survived longer than the median survival time (group B; table 1). In group $B$, there were fewer patients with diabetes mellitus ( $17 \%$ in group B vs. $58 \%$ in group A; $\mathrm{p}=$ 0.039). There were no differences between both groups in other comorbidities such as cerebrovascular accident, coronary artery bypass graft, peripheral arterial disease or chronic obstructive pulmonary disease. Mean age at start of PD in group B was lower than in group A (62 \pm 10 years in group $B$ vs. $71 \pm 8$ years in group $A ; p=0.013$ ). LVEF at start was not significantly different between both groups. Use of medications such as angiotensinconverting enzyme and angiotensin II inhibitors, diuretics, beta-blockers, statins and anticoagulation, was not different between both groups.

Body weight at start was lower in group $\mathrm{B}$ than in group A $(64.8 \pm 25.9$ vs. $74.9 \pm 13.0 \mathrm{~kg} ; \mathrm{p}=0.000)$. Adequacy of PD was not different between patients who survived less or more than 1 year.

Hospitalization for all causes was compared for groups $\mathrm{A}$ and $\mathrm{B}$ between the last year before starting dialysis and the 1st year after starting dialysis (table 2a). Hospitalization time for all causes was lower in group $B$ than in group A before starting dialysis $(3.7 \pm 3.8$ vs. $24.3 \pm 34.8$ days/ patient/month, respectively; $\mathrm{p}=0.040$ ) and after starting dialysis $(1.4 \pm 2.1$ vs. $13.3 \pm 12.2$ days/patient/month, 
respectively; $p=0.003$ ). In group $B$, hospitalization for all causes was decreased from $3.7 \pm 3.8$ days/patient/month before dialysis to $1.4 \pm 2.1$ days/patient/month after starting dialysis $(\mathrm{p}=0.041$ ), equivalent to a $62 \%$ reduction.

Also hospitalization for cardiovascular causes was compared between both groups (table 2b). Patients in group B were less frequently hospitalized for cardiovascular causes before starting dialysis (3.1 \pm 3.9 days/patient/month in group B and $24.2 \pm 34.9$ days/patient/ month in group $A ; p=0.026)$. In both groups, the hospitalization time for cardiovascular causes was reduced after starting dialysis [group A: $24.2 \pm 34.9$ before vs. $6.7 \pm 11.9$ days/patient/month after starting dialysis ( $\mathrm{p}=0.013$ ), equivalent to a $72 \%$ reduction, and in group B: $3.3 \pm 3.9$ before vs. $0.3 \pm 0.5$ days/patient/month after starting dialysis $(\mathrm{p}=0.008)$, equivalent to a $91 \%$ reduction].

Further, patients who started dialysis in an acute setting (during hospitalization; $\mathrm{n}=12$ ) were compared with patients who started in the outpatient setting. Patients in the outpatient setting started more frequently with $\mathrm{PD}$ $(83 \%)$, whereas patients in the acute setting were more frequently $(67 \%, \mathrm{p}=0.015)$ and longer treated with IHD (57 vs. 13 days, respectively; $p=0.020$ ). Patients with diabetes started less frequently in an acute setting (17 vs. $58 \%$, respectively; $\mathrm{p}=0.039$ ). Mean level of hemoglobin was higher in patients starting dialysis in the outpatient setting $(7.1 \pm 0.8$ vs. $6.4 \pm 0.8 \mathrm{mM}$, respectively; $\mathrm{p}=$ 0.045).

Hospitalization for cardiovascular causes was reduced for patients in the acute setting $(18.0 \pm 29.1$ before and $6.9 \pm 11.7$ days/patient/month after dialysis, $\mathrm{p}=0.041$, equivalent to a $62 \%$ reduction), as well for patients in the outpatient setting $(9.5 \pm 24.2$ before and $0.04 \pm 0.12$ days/patient/month after dialysis, $\mathrm{p}=0.003$, equivalent to a $99 \%$ reduction; table 3). But hospitalization time was lower for all causes and cardiovascular causes after starting dialysis in the outpatient setting $(2.4 \pm 4.1 \mathrm{vs} .12 .3 \pm$ 12.7 days/patient/month for all causes, $\mathrm{p}=0.035$, and 0.04 \pm 0.12 vs. $6.9 \pm 11.7$ days/patient/month for cardiovascular causes, $\mathrm{p}=0.000$; table 3 ).

Hospitalization times of group A patients who started dialysis in an acute and an outpatient setting were not different compared to group B (table 4a, b). Although, hospitalization of group B patients who started dialysis in the outpatient setting was reduced for all causes $(2.5 \pm$ 0.8 before vs. $0.9 \pm 1.1$ days/patient/month after starting dialysis, $\mathrm{p}=0.028$, equivalent to a $64 \%$ reduction) and for cardiovascular causes $(2.1 \pm 0.8$ before and $0.1 \pm 0.2$
Table 2. Hospitalization (number of days/patient/month) for all causes and cardiovascular causes before and after starting dialysis

a All causes

\begin{tabular}{lcc}
\hline & Before start & After start \\
\hline All patients $(\mathrm{n}=24)$ & $14.0 \pm 26.4$ & $7.4 \pm 10.5$ \\
Group A $(\mathrm{n}=12)$ & $24.3 \pm 34.8^{* *}$ & $13.3 \pm 12.2^{* * *}$ \\
Group B $(\mathrm{n}=12)$ & $3.7 \pm 3.8^{* * * *}$ & $1.4 \pm 2.1^{* * * *}$ \\
\hline
\end{tabular}

${ }^{*} \mathrm{p}=0.041,{ }^{* *} \mathrm{p}=0.040,{ }^{* * *} \mathrm{p}=0.003$.

Cardiovascular causes

\begin{tabular}{lcl}
\hline & Before start & After start \\
\hline All patients $(\mathrm{n}=24)$ & $13.7 \pm 26.5^{*}$ & $3.5 \pm 8.8^{*}$ \\
Group A $(\mathrm{n}=12)$ & $24.2 \pm 34.9^{* * \#}$ & $6.7 \pm 11.9^{* *}$ \\
Group B $(\mathrm{n}=12)$ & $3.3 \pm 3.9^{* * * \#}$ & $0.3 \pm 0.5^{* * *}$ \\
\hline
\end{tabular}

${ }^{*} \mathrm{p}=0.001,{ }^{* *} \mathrm{p}=0.013,{ }^{* * *} \mathrm{p}=0.008,{ }^{*} \mathrm{p}=0.026$.

Table 3. Hospitalization (number of days/patient/month) for patients starting dialysis in acute versus outpatient setting

$\begin{array}{ll}\text { Acute setting } & \text { Outpatient } \\ (\mathrm{n}=12) & \text { setting }(\mathrm{n}=12)\end{array}$

Hospitalization time for all causes

Before dialysis $\quad 18.2 \pm 29.0 \quad 9.7 \pm 24.1$

$\begin{array}{lll}\text { After dialysis } & 12.3 \pm 12.7^{*} & 2.4 \pm 4.1^{*}\end{array}$

Hospitalization time for cardiovascular causes Before dialysis $\quad 18.0 \pm 29.1^{\#} \quad 9.5 \pm 24.2^{\# \#}$

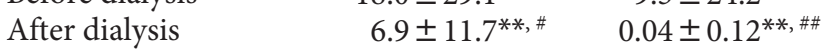

${ }^{*} \mathrm{p}=0.035,{ }^{* *} \mathrm{p}=0.000,{ }^{\#} \mathrm{p}=0.041,{ }^{\# \#} \mathrm{p}=0.003$.

days/patient/month after starting dialysis, $\mathrm{p}=0.018$, equivalent to a $95 \%$ reduction; table $4 \mathrm{~b}$ ).

There were no differences between first starting with IHD and first starting with PD with respect to mean age, mean diuresis, mean GFR, mean body weight, mean hemoglobin, mean CRP, mean serum albumin, LVEF predialysis, number of hospitalizations for all and cardiovascular causes and survival.

Complications related to PD technique (17\%) were pericatheter leakage $(n=1)$, recurrent peritonitis $(n=2)$ and umbilical hernia $(\mathrm{n}=1)$. Complications such as exit site infections, tunnel infections and catheter tip migration could not be retrieved in our population. 
Table 4. Hospitalization (number of days/patient/month) of groups A and B starting dialysis in acute versus outpatient setting

a Group A

\begin{tabular}{lcc}
\hline & $\begin{array}{l}\text { Acute setting } \\
(\mathrm{n}=7)\end{array}$ & $\begin{array}{l}\text { Outpatient } \\
\text { setting }(\mathrm{n}=5)\end{array}$ \\
\hline Hospitalization time for all causes & \\
Before dialysis & $27.4 \pm 35.8$ & $19.9 \pm 37.1$ \\
After dialysis & $19.5 \pm 11.9$ & $4.5 \pm 5.9$ \\
Hospitalization time for cardiovascular causes & \\
Before dialysis & $27.3 \pm 35.8$ & $19.8 \pm 37.1$ \\
After dialysis & $11.5 \pm 14.0$ & $0.00 \pm 0.00$ \\
\hline
\end{tabular}

No significant differences.

b Group B

\begin{tabular}{lll}
\hline & $\begin{array}{l}\text { Acute setting } \\
(\mathrm{n}=5)\end{array}$ & $\begin{array}{l}\text { Outpatient } \\
\text { setting }(\mathrm{n}=7)\end{array}$ \\
\hline Hospitalization time for all causes & \\
Before dialysis & $5.4 \pm 5.8$ & $2.5 \pm 0.8^{*}$ \\
After dialysis & $2.1 \pm 3.1$ & $0.9 \pm 1.1^{*}$ \\
Hospitalization time for cardiovascular causes \\
Before dialysis & $4.9 \pm 5.9$ & $2.1 \pm 0.8^{* *}$ \\
After dialysis & $0.6 \pm 0.6$ & $0.1 \pm 0.2^{* *}$ \\
\hline
\end{tabular}

${ }^{*} \mathrm{p}=0.028,{ }^{* *} \mathrm{p}=0.018$

\section{Discussion}

The present study has three important findings. First, survival in patients with treatment-resistant CHF complicated by severe renal failure is highly variable after starting PD. Secondly, age and diabetes mellitus, but not LVEF, seem to be prognostic factors with respect to 1-year survival. Thirdly, after starting PD, there was a reduction in hospitalization for all causes in patients who survived longer than 1 year and in all patients hospitalized for cardiovascular causes.

In our study, survival in treatment-resistant CHF was highly variable after starting PD. The mean survival in our study was 1.0 years, while 3 patients were still undergoing PD for more than 12 months at the end of followup. This is comparable with the study by Ryckelynck et al. [15], in which mean survival of 15 patients was 12.7 months, including 8 patients who were still undergoing treatment for more than 12 months. In the study by Elhalel-Dranitzki et al. [20], mean survival was 17 months including 4 patients who were still undergoing PD.
The patients in our study who survived longer than the median survival time were younger at starting PD, had lower prevalence of diabetes and were hospitalized less before starting dialysis. Probably they were in a better functional (and cardiovascular) condition than those who survived less than the median survival time. Also, in the 1st year after start of dialysis those patients had a significant reduction in hospitalizations for all causes and cardiovascular causes.

We could not reveal any correlation between LVEF at the beginning of dialysis and survival time after starting dialysis, as was earlier described by Hebert et al. [26]. Survival rate is usually correlated with LVEF at the beginning of treatment, but in our study mean LVEF assessed by echocardiography was not significantly higher in patients who survived longer than the median survival time. During follow-up, only 10 of the 18 patients who had a second echocardiography showed an improvement in LVEF. Probably due to intercurrent diseases and comorbidities such as diabetes, which could influence the (cardiovascular) condition and survival prognosis, LVEF does not always increase after starting dialysis. In the study by Kim et al. [6], 2 patients showed an improvement in LVEF, 1 patient had a stable LVEF and 1 patient had a deterioration in LVEF, although all patients exhibited a functional improvement by 1 or 2 NYHA classes after starting PD. Mehrotra and Kathuria [24] analyzed seven studies, and concluded that $>90 \%$ of the patients improved in functional status after starting dialysis. An important limitation of our retrospective study is that the change in functional status could not be retrieved.

In the present study, a reduction in hospitalization after starting dialysis for cardiovascular causes was observed in all patients. A reduction in hospitalization for all causes was only observed in patients who were treated longer than the median survival time. This finding is consistent with earlier studies [13-15, 20-23].

Hospitalization for cardiovascular causes was reduced for patients starting in the acute as well in the outpatient setting. In patients who survived longer than the median survival time and starting dialysis in an outpatient setting, hospitalization for all and cardiovascular causes was significantly reduced. Probably patients starting dialysis in the outpatient setting were in a better functional and more stable (cardiovascular) condition. They started more frequently with PD, had a higher mean hemoglobin concentration and more frequently diabetes.

In contrast, in our study the number of hospitalization days for all causes did not decrease in patients who were treated shorter than the median survival time, which did 
not appear to be primarily related to complications of $\mathrm{PD}$ treatment, but rather to a worsening of the general (cardiovascular) status of the patients. Also in the study performed by Rubin and Ball [27], hospitalization rates failed to improve due to dialysis complications and underlying heart disease.

In our study, patients who survived less than 1 year were significantly older and had significantly greater prevalence of diabetes. Older age and diabetes are probably important prognostic factors for survival in patients known with treatment-resistant CHF complicated by severe renal failure and treatment with $\mathrm{PD}$. This finding is consistent with earlier studies.

A reduction in hospitalization and an improvement in functional status after starting PD in treatment-resistant $\mathrm{CHF}$, could consequently lead to an improvement in quality of life. In only two observational studies was the quality of life assessed. First, in the study by Stegmayr et al. [18], 16 patients with known CHF were treated with $\mathrm{PD}$, and within 1 month all patients improved in functional status and also in quality of life. In the study by Bertoli et al. [25], only 2 patients with known CHF were treated with a single nocturnal exchange with icodextrin. After at least 12 months of treatment, a reduction in morbidity and hospitalization was seen, as well as a significant improvement in the quality of life in both patients. More studies are needed to confirm these data.

Use of icodextrin, a glucose polymer, might be particularly interesting in patients with hypervolemic treatment-resistant CHF because of the ability to generate sustained ultrafiltration over periods of long dwells and to allow euvolemia by a single nocturnal exchange. It may reduce ECF volume, TBW and BW due to better ultrafiltration and sodium losses [28-32]. Furthermore, it contains a lower concentration of glucose degradation products than conventional PD fluids. In the present study, only 13 of the 24 patients (54\%) used icodextrin. This number of patients was too small in order to reveal any correlation with outcome parameters. Further, body weight was significantly reduced after starting PD. This may reflect the increased sodium removal and results in a reduced number of hospitalizations. Patients who survived less than 1 year had significantly higher body weight at start of dialysis. Probably, these patients were more hypervolemic before starting dialysis and consequently in a worse (cardial) condition. This may suggest that dialysis should be started in time in patients with CRS and progressive chronic renal insufficiency.

Limitations of the present study are its retrospective design, the limited number of patients over a relatively long observation period and the absence of detailed information on functional status, quality of life and fluid status. Prospective studies are needed to find out more about the effect and outcome of dialysis in patients with known treatment-resistant CHF.

\section{Conclusion}

In our opinion, based on the results in the literature and our own clinical experience, PD is a feasible therapy in a selected group of patients with treatment-resistant CHF complicated by severe renal failure. However, after starting PD we observed a reduction in hospitalization for cardiovascular causes for all patients, but a reduction in hospitalization for all causes was only observed in patients who survived longer than the median survival time. Age and diabetes mellitus, but not LVEF, appeared to be important prognostic factors with respect to survival. However, patient selection remains difficult. Further investigations are needed to clearly define the criteria for starting PD in CRS type II.

References

1 Ronco C, Chionh C, Haapio M, Anavekar NS, House A, Bellomo R: The cardiorenal syndrome. Blood Purif 2009;27:114-126.

2 Riley DJ, Weir M, Bakris GL: Renal adaptation to the failing heart: avoiding a 'therapeutic misadventure'. Postgrad Med 1994;95: 153-164.

- 3 Ellison DH: Diuretic drugs and the treatment of edema: from clinic to bench and back again. Am J Kidney Dis 1994;23:623643 .

4 Elisson DH: Diuretic combinations in the treatment of edema: rationale and recommendations. Drug Ther 1994;24:23-33.

5 Robson M, Biro A, Kobel B, Schai G, Ravid $\mathrm{M}$ : Peritoneal dialysis in congestive heart failure I - continuous ambulatory peritoneal dialysis. Perit Dial Bull 1983;3:133-136.

6 Kim D, Khanna R, Wu G, Fountas P, Druck N, Oreopoulos DG: Successful use of continuous ambulatory peritoneal dialysis in congestive heart failure. Perit Dial Bull 1983;3: 133-134.

7 Konig P, Geissler D, Lechleitner P, Spielberg $\mathrm{M}$, Dottarch P: Improved management of congestive heart failure. Use of continuous ambulatory peritoneal dialysis. Arch Intern Med 1987;147:1031-1034.

8 Nakajima U, Suga T, Ishida K: Successful use of continuous ambulatory peritoneal dialysis (CAPD) in the treatment of patients with renal and cardiac failure. Tokai J Exp Clin Med 1986;11:774-783. 
$>9$ Rubin J, Ball R: Continuous ambulatory peritoneal dialysis as a treatment of severe congestive heart failure in the face of chronic renal failure. Report of eight cases. Arch Intern Med 1986;146:533-535.

10 Stegmayr BG, Lundberg L, Widahl AM, Wirell-Plum M: Severe heart failure (sHF): an indication for ultrafiltration by peritoneal dialysis techniques. Perit Dial Int 1994; 14:S62.

11 Van der Sande FM, Kho L, Leunissen KML: Effects of continuous ambulatory peritoneal dialysis in the treatment of patients with therapy-resistant congestive heart failure and (pre)renal failure (personal observations, 1996).

12 Bertoli S, Ciurlino D, Martino S, Maccario M, Ballabeni C: Ultrafiltrative peritoneal treatment in patients with severe congestive heart failure (NYHA class III-IV) and moderate to severe chronic renal insufficiency (CRI). Perit Dial Int 2004;24:S31.

-13 Mehrotra R, Khanna R: Peritoneal ultrafiltration for chronic congestive heart failure: rationale, evidence and future. Cardiology 2001;96:177-182.

-14 Ortiz AM, Acosta PA, Corbalan R, Jalil JE: Long-term automated peritoneal dialysis in patients with refractory congestive heart failure. Adv Perit Dial 2003;19:77-80.

15 Ryckelynck JP, Lobbedez T, Valette B, Le Goff C, Mazouz O, Levaltier B, Potier JC, Hurault de Ligny B: Peritoneal ultrafiltration and refractory congestive heart failure. Adv Perit Dial 1997;13:93-97.

-16 McKinnie JJ, Bourgeois RJ, Husserl FE: Long-term therapy for heart failure with continuous ambulatory peritoneal dialysis. Arch Intern Med 1985;145:1128-1129.

17 Mousson C, Tanter Y, Chalopin JM, Rebibou JM, Dentam G, Morelon P, Rifle G: Treatment of refractory congestive cardiac insufficiency by continuous peritoneal dialysis. Long-term course. Presse Med 1988;17:16171620 .
18 Stegmayr BG, Banga R, Lundberg L, Wikdahl AM, Plum-Wirell M: PD treatment for severe congestive heart failure. Perit Dial Int 1996;16(suppl 1):S231-S235.

19 Bilora F, Petrobelli F, Boccioletti V, Pomerri F: Treatment of heart failure and ascites with ultrafiltration in patients with intractable alcoholic cardiomyopathy. Panminerva Med 2002;44:23-25.

20 Elhalel-Dranitzki M, Rubinger D, Moscovici A, Haviv YS, Friedlaender MM, Silver J, Popovtzer MM: CAPD to improve quality of life in patients with refractory heart failure. Nephrol Dial Transplant 1998;13:30413042.

21 Freida P, Ryckelynck JP, Potier J, Hurault de Ligny B, Mazouz O, Al Halabi A: Place de l'ultrafiltration péritonéale dans le traitement médical de l'insuffisance cardiaque au stade IV de la NYHA. Bull Dial Perit 1995;5: 7-18.

22 Tormey V, Conlon PJ, Farrell J, Horgan J, Walshe JJ: Long-term successful management of refractory congestive cardiac failure by intermittent ambulatory peritoneal ultrafiltration. QJM 1996;89:681-683

23 Gotloib L, Fudin R, Yakubovich M, Vienken $\mathrm{J}$ : Peritoneal dialysis in refractory end-stage congestive heart failure: a challenge facing a no-win situation. Nephrol Dial Transplant 2005;20:32-36.

24 Mehrotra R, Kathuria P: Place of peritoneal dialysis in the management of treatment-resistant congestive heart failure. Kidney Int 2006:70;67-71.

25 Bertoli SV, Ciurlino D, Maccario M, Martino S, Bigatti G, Traversi L, Procaccio M, Buzzi L: Home peritoneal ultrafiltration in patients with severe congestive heart failure without end-stage renal disease. Adv Perit Dial 2005; 21:123-127.
26 Hebert MJ, Falardeau M, Pichette V, Houde M, Nolin L, Cardinal J, Ouimet D: Continuous ambulatory peritoneal dialysis for patients with severe left ventricular systolic dysfunction and end-stage renal disease. Am J Kidney Dis 1995;25:761-768.

27 Rubin J, Ball R: Continuous ambulatory peritoneal dialysis as treatment of severe congestive heart failure in the face of chronic renal failure. Report of eight cases. Arch Intern Med 1986;146:1533-1535.

28 Plum J, Gentile S, Verger C, Brunkhorst R, Bahner U, Faller B, Peeters J, Freida P, Struijk DG, Krediet RT, Grabensee B, Tranaeus A, Filho JC: Efficacy and safety of a $7.5 \%$ icodextrin peritoneal dialysis solution in patients treated with automated peritoneal dialysis. Am J Kidney Dis 2002;39:862-871.

$\checkmark 29$ Woodrow G, Oldroyd B, Stables G, Gibson J, Turney JH, Brownjohn AM: Effects of icodextrin in automated peritoneal dialysis on blood pressure and bioelectrical impedance analysis. Nephrol Dial Transplant 2000;15: 862-866.

>30 Davies SJ, Woodrow G, Donovan K, Plum J, Williams P, Johansson AC, Bosselmann HP, Heimburger O, Simonsen O, Davenport A, Tranaeus A, Divino Filho JC: Icodextrin improves the fluid status of peritoneal dialysis patients: results of a double-blind randomized controlled trial. J Am Soc Nephrol 2003; 14:2338-2344.

31 Konings CJ, Kooman JP, Schonck M, Gladziwa U, Wirtz J, van den Wall Bake AW, Gerlag PG, Hoorntje SJ, Wolters J, van der Sande FM, Leunissen KM: Effect of icodextrin on volume status, blood pressure and echocardiographic parameters: a randomized study. Kidney Int 2003;63:1556-1563.

32 Boudville NC, Cordy P, Millman K, Fairbairn L, Sharma A, Lindsay R, Blake PG: Blood pressure, volume, and sodium control in an automated peritoneal dialysis population. Perit Dial Int 2007;27:537-543. 